\title{
Cleft Lip Surgical Intervention in Resource Constraint Settings: A Case Report
}

\author{
Anant Kumar ${ }^{1,2}$, Loree K. Kalliainen ${ }^{3}$ \\ ${ }^{1}$ Gillings School of Global Public Health, University of North Carolina, Chapel Hill, NC, USA \\ ${ }^{2}$ Xavier Institute of Social Service, Ranchi, India \\ ${ }^{3}$ School of Medicine, University of North Carolina, Chapel Hill, NC, USA \\ Email: anant22@live.unc.edu
}

Received 29 January 2016; accepted 15 March 2016; published 18 March 2016

Copyright (C 2016 by authors and Scientific Research Publishing Inc.

This work is licensed under the Creative Commons Attribution International License (CC BY). http://creativecommons.org/licenses/by/4.0/

\section{c) (i) Open Access}

\begin{abstract}
Cleft lip and palate is a very common condition which is globally undertreated. This case report shows how cleft lip surgery can transform patient's lives, self-perception, and their self-esteem through a visionary and adaptive leadership of a few social workers and medical doctors in resource constrained settings. The case report also shows that when treated, the benefits to the patient and their family are lifelong and disproportionately large compared to the degree of effort and cost of doing the reconstruction; and puts forth the case for educating physicians to maximize their societal benefit through work in resource-constrained settings.
\end{abstract}

Keywords

Cleft Lip, Self-Esteem, Social Perception, Women's Health, Resource-Constrained, India

\section{Introduction}

Cleft lip and palate (CLP) is a congenital, polygenically-inherited malformation found globally. It affects patients' lives in multiple ways, which includes their social, psychological, and mental wellbeing, due to poor acceptance, social stigma, taboo, and negative perception. The incidence of cleft lip is relatively constant worldwide at approximately 1:700 live births [1] [2]. Although cost effective treatment is possible at relatively low-risk, it is not available to all [2]. The total cost of care for patients with cleft lip varies. Operation Smile, a United States-based international non-profit surgical service organization dedicated to the correction of cleft lip and palate, has estimated the costs to range between 85 - 630 USD per patient depending on the patient's geographical location [3]. Per patient costs of Smile Train (another non-profit organization dedicated to the care of children with cleft lip and palate) in India have been estimated to be Rupees 13,500 (340 USD) [4]. Surgical 
treatment is required to correct the facial deformity, and other interventions are recommended to address associated difficulties in feeding, speech, and hearing. Multiple studies have demonstrated that people born with clefts are less likely to get married and have a higher incidence of emotional difficulties. Interestingly, most of the research has been done on people with repaired clefts; few studies have looked at the effects of unrepaired cleft on an individual's life [5]-[7]. The necessity of cleft lip repair is debated in the past as a "cosmetic" issue, but an extensive body of research has shown that beauty (or lack of deformity) matter for social, economic, and educational purposes [8]-[11]. It has been estimated that only $4 \%$ of all surgical procedures performed in the world are done to benefit the poorest one-third of the population [12]. Operation Smile estimates that surgeons associated with their organization have corrected over 220,000 cleft lips world-wide since 1982. If one estimates the worldwide population at 7 billion and 1:700 live births have CL/P, it can be conservatively estimated that 10 million people are living with CL/P. With a population of 1.27 billion, approximately 1.8 million people in India have CL/P. Though the aforementioned NGOs are providing laudable services and are working with countries to educate providers and build infrastructure, potential demand far outstrips the supply.

\section{Background}

Holy Cross Hospital, established in 1973, is a seventy bed hospital located in a remote area in Belatanr in the Giridih district of Jharkhand, India, run by the Sisters of Mercy of the Holy Cross (SCSC). Jharkhand is an eastern state with a population of 33 million. Approximately $26.3 \%$ of the population is tribal. The Giridih district was rated as one of the backward districts in India in 2006, and the government has provided assistance to support development in the area [13]. The area is remote with limited health services; and the Sisters are working diligently to improve people's lives. The Sisters have been active for more than forty years in improving the health and social aspects of the lives of people in their district. Their medical team is led by two Doctor Sisters: one is trained in general surgery and other in obstetrics and gynecology. Local physicians also use the Holy Cross clinic space to see patients. No medical trainees have been incorporated into their system.

In addition to medical and surgical care, the Sisters promote public health through maternal and prenatal education, malaria prevention, care of people with Hansen's Disease (Leprosy), childhood nutrition and vaccinations. They run a primary school for local children, have a hostel for children who live too far away to walk to school, and educate young Santhali women in homemaking skills and traditional crafts. They do some nursing training, and they envision creating a nursing school. They have made connections with physicians and surgeons from Germany and the United States, leading to the formation of the Plastic Surgery Camp. Despite their concern and willingness, the Sisters were not able to provide cleft lip or complex burn care outside of the plastic surgery camps due to direct and indirect costs, shortage of well trained manpower, and the inability of patients to pay.

\section{Case Report}

Holy Cross Hospital organizes an annual Plastic Surgery camp with the help and support of Plastic Surgeons and their team from multiple locations in the USA. Sisters do an initial triage before the team arrives. A team of doctors then re-screens the patients and performs surgery for a week. The majority of patients treated in the camps are children; a little less than half have cleft lips, and the remainder have significant burn scar contractures. Adult women also come to the camp for treatment; their problem is usually a scarred face and neck from a burn.

Devki, a 43 year old woman, presented in 2007 with the problem of a cleft lip. She was born with a cleft lip and lived a relatively marginalized life within her village. She had a defeated look on her face. Not many good things had ever happened to her in her life, and she was not expecting much to happen in the future. One could read that easily on her sad face (Figure 1(a)). She heard about a Plastic Surgery Camp to be held at Holy Cross Hospital and was able to successfully undergo life-changing reconstructive surgery. The doctor examined her and admitted her for surgery. With the help of translating Sister Nurses, the doctor told her that her lip could be fixed, but her speech would likely never be completely normal. The repair was very straightforward, taking less than one hour to complete. After the surgery, she was discharged without any complication.

In early 2015, the doctor visited again and she was surprised to see that Devki came to see her. She had a huge smile on her face, she was beautiful (Figure 1(b)), and they hugged each other for a long time. Some messages don't need a shared language. Devki told Dr. Sister that before surgery, she had been called Dayan (witch); 


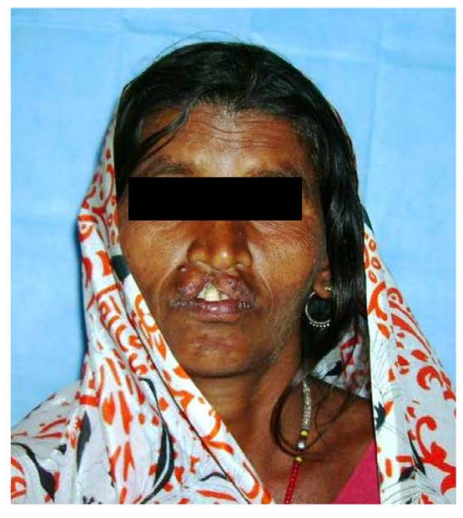

(a)

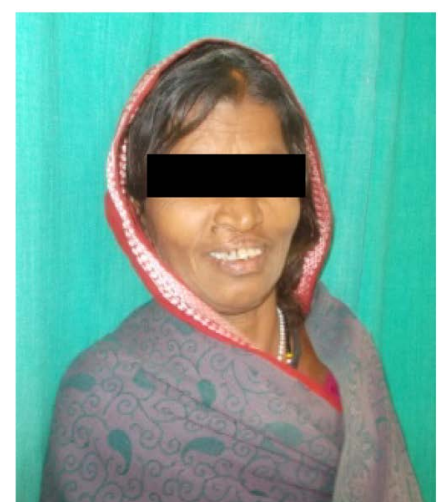

(b)

Figure 1. (a) Pre-operative (2007); (b) Post-operative(2015).

now people are addressing her with respect (Aunt). She mentions that now she is happy with her family and got a new life by this cleft lip operation. It has changed people's perception towards her. Now she is welcomed everywhere and she gives this credit to the Sisters and the team of doctors.

Devki's gratitude towards the doctor was not a surprise as many patients thank their doctor for successful operations, treatments or cures. However, the gratitude was not only for the operation, treatment or the cure. It was for giving her a new life, a new identity and a respect. The doctor after meeting Devki said, "There are times when we can do an operation, and though it may be a technical success, if the person's mind can't cope with the change, it is a failure. Fortunately, for this lady, she was able to bounce back and create a happier life not only for herself, but also for her family".

\section{Issues for Discussion}

This case study is meant to bring several issues into focus. Access to necessary surgery is a public health issue. Being able to receive care locally is cost-effective, builds strong community, and allows people to be active socially and economically [8] [14]-[16]. Thus, it is suggested that surgical trainees must be specifically educated on the development of surgical decision making skills, self-reliance, self-awareness, self-education, and resource accrual in resource-constrained locales. They must have role models for this form of practice, receive part of their training in these environments, and be supported in their efforts to provide care where care is needed. In underserved areas, constraints exist in every element of care. The surgeon must be skilled in patient selection, technique and in resource management as poor decision-making has negative effects on both treated and untreated patients. It has been estimated that poor surgical technique leads to one million deaths and seven million complications each year worldwide [17].

\subsection{Patient Selection}

Patient selection is a very important step. It requires consideration of the resources available as well as the expertise of the consultant surgeon. The surgeon must ask himself or herself a number of questions. Am I certain of the diagnosis? What is the surgical and medical history? Does the patient have other untreated medical conditions? Will his or her nutritional status allow healing, and will the operated body part heal? Besides physical factors, the social situation must be explored. Is the person a smoker? Is someone available to care for him or her? How well is the patient coping with the condition currently, and can I make a significant improvement in quality of life? What are the patient's expectations? What are the options if the first option fails? The overarching question: what is the risk: benefit ratio for proffered treatment?

In patient selection, training and experience play an important role in the application of surgical judgement and technical skills. Wisdom, self-awareness, and self-confidence are especially important when a doctor has limited supplies, personnel, and infrastructure. In hospital settings, one is surrounded by experts and colleagues with different areas of specialization and expertise, and collaboration is straightforward. When developing a practice in resource-constrained settings, expectations and plans have to be adjusted. The surgeon must be very 
systematic about the approach to patients. Clinical practice guidelines must prioritize patient safety and selection, or avoidable complications and loss of trust in the surgeon will occur [18]. The more rudimentary the system, the more selective the surgeon must be in choosing both the patient and the procedure. If one is trying to have maximal impact, an operation that might not be considered the 'best' in a tertiary care center may be chosen. If one is not choosing the "gold standard", but the silver or bronze option, there should be a valid reason arrived at by weighing all key factors. For this reason, the team must include a family physician. If the family physician has concerns about the patient's overall health, they should not be operated on in the resource-constrained location. If a surgeon knows from prior experience that a patient may have excessive bleeding, require prolonged recovery, or need complex post-operative care, the patient should be referred to a larger center. Likewise, if the diagnosis is unclear and if ancillary tests or multi-specialty care are necessary, the patient should be sent to a larger referral center. That they may need to travel a long distance or may not be happy not to be operated on closer to home is irrelevant.

Any operation should provide a benefit; the surgeon and patient must decide together, how much risk and benefit are acceptable and achievable. Shared decision making is gaining in popularity in the US, Canada, and Europe, but it has not become a global standard [19]-[22]. Some physicians still believe that patients cannot adequately understand their options, but optimal communication and education are crucial. In the setting of a less-than-desirable outcome, patients are more understanding if they have been educated ahead of time [21].

\subsection{Surgical Management}

Surgeons must become very aware of their personal capacity and limitations. Learning from one's experience is humbling, but to gain the benefit of experience, the surgeon must do ongoing chart reviews and keep a record of his or her outcomes. When there is a negative outcome, there can be an understandable and human tendency to blame the patient or other external factors, but it is the surgeon's responsibility to ask how he or she contributed to the outcome and what could have been done to prevent it [23]. The isolated surgeon must develop an acute awareness of his or her individual capacity and be willing to gently yet steadily work on their skills and push boundaries to meet local needs. The surgeon must be extraordinarily self-critical and take small steps to allow outcomes to be assessed before proceeding to the next level of care. When doing a new procedure, the questions must be asked: 1) Where am I on the learning curve? 2) Is this the best that I can do? 3) Is this the best that can be done?

Plastic surgeons are taught the philosophy of the reconstructive ladder: the list of ways to address a problem starting from basic techniques and moving toward more complex ones. Any surgeon should be skilled at basic levels before attempting more challenging procedures. During surgical planning, it is important for the less-experienced surgeon to appropriately prepare. The surgeon should initially perform the exercise of listing all possible surgical options with the benefits and risks of each. It is crucial to acknowledge the most likely complications of each option and their chance of occurrence, and to create a plan for each complication. If the basic complications cannot be handled by the operating surgeon, the procedure should be done under the guidance of an expert. Reading at least three techniques papers, writing down the steps, drawing the planned procedure, and watching available videos should all precede attempts at performing any new procedure. Eventually, this process becomes second nature, but preoperative planning saves time and heartache.

One of the most commonly seen surgical problems globally is cleft lip/palate [3]. The basic principles of cleft lip repair are straightforward when one has moderately well-developed surgical skills. As long as the surgeon recognizes the key problem-a lack of tissue on the cleft side-the need to do a rotation and advancement of all layers of tissue from the contralateral side becomes more obvious. A straight line repair of a cleft lip is a novice mistake often made by surgeons without Plastic Surgery training. A straight line repair will never provide a good result. The scar will contract and create a notched lip (at best) or create a different form of deformity. Correction of the cleft lip nasal deformity is more complex than the correction of the lip and requires a more sophisticated level of understanding of bony deformities and classic patterns of soft tissue deformity as well as a higher level of surgical technique. In the current literature reviewing social outcomes in patients with cleft lip, it has been recognized that there is ongoing social anxiety even if the lip has been properly fixed [5]-[7]. The psychosocial outcomes of poor surgical technique have not been studied, but the patient deserves the best chance for a good outcome, and lack of awareness of technique is not appropriate.

Differences in surgical safety vary by an order of magnitude between developed and developing countries. In 
the United States, for example, the intraoperative death rate for inpatients is $0.8 \%$. In developing and underdeveloped countries, the death rate is as high as $10 \%$ [24].

\subsection{Resource Management}

Resources include infrastructure, equipment, and well trained people. When entering a highly constrained area, the system may consist of a few staff members. Creating a vision and goals for the group, documenting the organizational structure, and scheduling times to review progress and successes are crucial. Otherwise, the team may flounder and feel disappointed when the same problems are faced time and again. Though it may be time intensive at the beginning, creating a systematized approach to patient care and outcomes measurement will save time and create opportunities in the future. Building support from local business leaders and educators helps in creating support for health care initiatives, and creating supportive mentorship connections outside of the community helps keep the isolated surgeon aware of educational opportunities when the surgeon is not fortunate enough to be surrounded by peers with whom to consult.

Physical resources such as lab equipment, hospital beds, suture material, and surgical tools may be the most difficult to gather; making connections with NGOs and finding opportunities for government and international grants can aid in finding the equipment needed [25]. Visiting surgical teams can provide education in technique, infrastructure, and leadership, as well as create connections and the opportunity for mentorship [26] [27]. Local and regional care centers have been found to have similar cost-benefit ratios and therefore both options should be explored. Creating connections via telemedicine can take advantage of expertise of colleagues around the world [28]. There are not enough visiting foreign surgeons to care for every person born with a cleft in developing countries; thus, local capacity must be developed to allow for continuous care to be provided. This applies to all surgical problems.

\section{Conclusions}

This case highlights three important issues: relatively straightforward surgical procedures such as cleft lip repair can change lives, extensive resources are not mandatory to provide basic surgical care, and systems must be created to combine trained providers with in-need patients. Given the large number of children born each year with cleft lip, the demand currently far outstrips supply, and this reality, unfortunately, leaves millions of children and adults with unrepaired clefts. This case shows how even with limited resources and facilities, the Holy Cross Sisters are improving their neighbors' lives by collaboration with visiting surgeons. Thus, there is a need to develop a mechanism to allow reproduction of their work by local surgeons to continue this work benefitting the needy people in a resource constrained setting.

This case also reinforces the need to train new medical graduates in developing countries on how to effectively deliver services to the most needy in resource-constrained settings. The public health system and government need to work with local providers, families, and patients to create a functional care web that allows patients to access the care most appropriate to their needs and to support surgeons in their ability to provide local care whenever possible. Creating centers of excellence to which patients must travel seems, on the surface, to be a logical step, but it may be highly impractical in underdeveloped countries. For multiple valid reasons, patients may simply not have the ability to travel to those centers. The ability to provide care for common conditions such as cleft lip must be expanded. The paper suggests that surgical trainees need to gain the skills to be able to practice safely, effectively and efficiently in resource-constrained settings and to gradually improve the complexity of care provided at the local level. The Government must identify strategies to educate and support local surgeons who will enjoy the challenges inherent in this type of practice and help them create their teams.

\section{Conflict of Interest}

The authors declare that they have no conflicts of interests.

\section{Acknowledgements}

Authors confirm that the patient has given her consent for the case report to be published. They are thankful to Rohit Ramaswamy, Dilshad Jaff, Gabriela Reed and Jeyhan Wood for their comments and suggestions on the case report. They also acknowledge the generous support to cover the publication fee by the Public Health Lea- 
dership Program, UNC Gillings School of Global Public Health.

\section{Notes}

The Santhal or Saontal are a scheduled tribe of indigenous to Terai of Nepal and India, who live mainly in Nepal and the Indian States of Jharkhand, West Bengal, Bihar, Odisha, and Assam.

\section{References}

[1] Vanderas, A.P. (1987) Incidence of Cleft Lip, Cleft Palate, and Cleft Lip and Palate among Races: A Review. Cleft Palate-Craniofacial Journal, 24, 216-225.

[2] Mossey, P.A., Shaw, W.C., Munger, R.G., Murray, J.C., Murthy, J. and Little, J. (2011) Global Oral Health Inequalities: Challenges in the Prevention and Management of Orofacial Clefts and Potential Solutions. Advances in Dental Research, 23, 247-258. http://dx.doi.org/10.1177/0022034511402083

[3] Magee, W.P., Vander Burg, R. and Hatcher, K.W. (2010) Cleft Lip and Palate as a Cost-Effective Health Care Treatment in the Developing World. World Journal of Surgery, 34, 420-427. http://dx.doi.org/10.1007/s00268-009-0333-7

[4] Iyer, M. (2013) 1 in 1,000 Indian Kids Born with a Cleft Lip. Times of India. http://timesofindia.indiatimes.com/india/1-in-1000-Indian-kids-born-with-a-cleft-lip/articleshow/21063303.cms

[5] Berk, N.W., Cooper, M.E., Liu, Y.E. and Marazita, M.L. (2001) Social Anxiety in Chinese Adults with Oro-Facial Clefts. Cleft Palate-Craniofacial Journal, 38, 126-133. http://dx.doi.org/10.1597/1545-1569(2001)038<0126:SAICAW>2.0.CO;2

[6] Hamlet, C. and Harcourt, D. (2015) Older Adults’ Experiences of Living with Cleft Lip and Palate: A Qualitative Study Exploring Aging and Appearance. Cleft Palate-Craniofacial Journal, 52, e32-e40. http://dx.doi.org/10.1597/13-308

[7] Roberts, R.M. and Mathias, J.L. (2012) Psychosocial Functioning in Adults with Congenital Craniofacial Conditions. Cleft Palate-Craniofacial Journal, 49, 276-285. http://dx.doi.org/10.1597/10-143

[8] Muntz, H.R. and Meier, J.D. (2013) The Financial Impact of Unrepaired Cleft Lip and Palate in the Philippines. International Journal of Pediatric Otorhinolaryngology, 77, 1925-1928. http://dx.doi.org/10.1016/j.ijporl.2013.08.023

[9] Naram, A., Makhijani, S.N., Naram, D., Reddy, S.G., Reddy, R.R., Lalikos, J.F. and Chao, J.F. (2013) Perceptions of Family Members of Children with Cleft Lip and Palate in Hyderabad, India, and Its Rural Outskirst Regarding Craniofacial Anomalies: A Pilot Study. Cleft Palate-Craniofacial Journal, 50, e41-e47. http://dx.doi.org/10.1597/10-170

[10] Pruzinsky, T. (1992) Social and Psychological Effects of Major Craniofacial Deformity. Cleft Palate-Craniofacial Journal, 29, 578-584. http://dx.doi.org/10.1597/1545-1569(1992)029<0578:SAPEOM >2.3.CO;2

[11] Qingguo, M. and Yue, H. (2015) Beauty Matters: Social Preferences in a Three-Person Ultimatum Game. PLoS ONE, 10, e0125806. http://dx.doi.org/10.1371/journal.pone.0125806

[12] Operation Smile. http://www.operationsmile.org/surgery/global-need

[13] National Institute of Rural Development. Ministry of Panchayati Raj (September 8, 2009) A Note on the Backward Regions Grant Fund Programme. http://www.nird.org.in/brgf/doc/brgf_BackgroundNote.pdf

[14] Ivers, L.C., Garfein, E.S., Augustin, J., Raymonville, M., Yang, A.T., Sugarbaker, D.S. and Farmer, P.E. (2008) Increasing Access to Surgical Services for the Poor in Rural Haiti: Surgery as a Public Good for Public Health. World Journal of Surgery, 32, 537-542. http://dx.doi.org/10.1007/s00268-008-9527-7

[15] McQueen, K.A., Ozgediz, D., Riviello, R., Hsia, R.Y., Jayaraman, S., Sullivan, S.R. and Meara, J.G. (2010) Essential Surgery: Integral to the Right to Health. Health Hum Rights, 12, 137-152.

[16] Mock, C., Cherian, M., Juillard, C., Donkor, P., Bickler, S., Jamison, D. and McQueen, K. (2010) Developing Priorities for Addressing Surgical Conditions Globally: Furthering the Link between Surgery and Public Health Policy. World Journal of Surgery, 34, 381-385. http://dx.doi.org/10.1007/s00268-009-0263-4

[17] Weiser, T.G., Makary, M.A., Haynes, A.B., et al. (2009) Standardised Metrics for Global Surgical Surveillance. The Lancet, 374, 1113-1117. http://dx.doi.org/10.1016/S0140-6736(09)61161-2

[18] Saleem, L. and John, J.R. (2013) Unfavourable Results Following Reduction Mammoplasty. Indian Journal of Plastic Surgery, 46, 401-407. http://dx.doi.org/10.4103/0970-0358.118620

[19] Seal, R.P., Kynaston, J., Elwyn, G. and Smith, P.E.M. (2014) Using an Option Grid in Shared Decision Making. Pract Neurol, 14, 54-56. http://dx.doi.org/10.1136/practneurol-2013-000666

[20] Flierler, W.J., Nubling, M., Kasper, J. and Heidegger, T. (2013) Implementation of Shared Decision Making in Anaesthesia and Its Influence on Patient Satisfaction. Anaesthesia, 68, 713-722. http://dx.doi.org/10.1111/anae.12196

[21] Franzblau, L.E., Maynard, M., Chung, K.C. and Yang, L.J.S. (2015) Medical Treatment Decision Making after Total 
Avulsion Brachial Plexus Injury: A Qualitative Study. Journal of Neurosurgery, 122, 1413-1420. http://dx.doi.org/10.3171/2015.2.JNS132686

[22] Joosten, E.A.G., De Fuentes-Merillas, L., de Weert, G.H., Sensky, T., van der Staak, C.P.F. and de Jong, C.A.J. (2008) Systematic Review of the Effects of Shared Decision-Making on Patient Satisfaction, Treatment Adherence and Health Status. Psychother Psychosom, 77, 219-226. http://dx.doi.org/10.1159/000126073

[23] Hentz, V.R. (2002) Surgical Strategy: Matching the Patient with the Procedure. Hand Clinics, 18, 503-518. http://dx.doi.org/10.1016/S0749-0712(02)00030-6

[24] WHO Safe Surgery Saves Lives: Second Global Patient Safety Challenge. WHO/IER/PSP/2008.07. http://www.who.int/patientsafety/safesurgery/knowledge_base/SSSL_Brochure_finalJun08.pdf

[25] Adegbehingbe, O.O., Akinyoola, A.L., Ariyibi, A.L. and Oginni, L.M. (2009) Direct Integration of Government Funding and Family Support for Musculoskeletal Tumor Care in a Resource-Constrained Country.Oncology, 76, 398-404. http://dx.doi.org/10.1159/000215926

[26] Bido, J., Singer, S.J., DiezPortela, D., Ghazinouri, R., Driscoll, D.A., Alcantara Abreu, L., Aggouras, B.M., Thornhill, T.S. and Katz, J.N. (2015) Sustainability Assessment of a Short-Term International Medical Mission. The Journal of Bone \& Joint Surgery, 97, 944-949. http://dx.doi.org/10.2106/JBJS.N.01119

[27] Eberlin, K.R., Vyas, R.M., Abi-Haidar, Y., Sethna, N. and Hamdan, U.S. (2013) Adult Cleft Lip Repair under Local Anesthesia: An Effective Technique in Resource-Poor Settings. Cleft Palate-Craniofacial Journal, 50, 59-63. http://dx.doi.org/10.1597/11-256

[28] Fuzaylov, G., Anderson, R., Knittel, J. and Driscoll, D.N. (2015) Global Health: Burn Outreach Program. Journal of Burn Care \& Research, 36, 306-309. http://dx.doi.org/10.1097/BCR.0000000000000074 